\title{
Report on the Meeting of Presidents of Mathematical Societies in Budapest, 2-3 April 2016
}

Sjoerd Verduyn Lunel, Secretary of the EMS, and Richard Elwes, EMS Publicity Officer

Pavel Exner, President of the European Mathematical Society and Chair of the meeting, opened proceedings by greeting everyone present and thanking our hosts, the Alfred Rényi Institute of Mathematics of the Hungarian Academy of Sciences. After a Tour De Table in which the guests introduced themselves and their Society, Gyula Katona, President of the János Bolyai Mathematical Society delivered a presentation on its fascinating history as well as its current activities.

\section{EMS Business}

Pavel Exner gently reminded the assembled company of the importance of member societies and individuals paying their dues on time. (If they have difficulty doing so, they should get in touch with the EMS directly to negotiate an arrangement.)

The Chair reported on the EMS's wide range of scientific activities, and encouraged member societies to prepare proposals for scientific activities, such as Joint 
Mathematical Weekends. (Proposals for 2017 can be submitted via the EMS website.)

After discussing the work of the EMS's eleven Standing Committees, he spoke about its online presence, a major way of keeping in contact with members and the broader mathematical community. He encouraged member societies to get involved, and to contact Richard Elwes, Publicity Officer of the EMS, with any new ideas in this area.

\section{Presentations}

The meeting then heard a number of presentations:

- Volker Bach described progress towards the 7th ECM (Berlin, 18-22 July 2016)

- Betül Tanbay, member of the EMS Ethics Committee, reported on its work on the application of the EMS Code of Practice and towards a new edition of the Code in due course. She welcomed comments and suggestions for additional areas to be addressed, for example, regarding unethical behaviour with respect to 'open access' publications.

- Waclaw Marzantowicz, President of the Polish Mathematical Society, reported on its recently established Mathematical Information Service.

- Mercedes Siles Molina, Vice-President of the Royal Spanish Mathematical Society (RSME), described connections between RSME and the mathematical societies of South America. She stressed that the RSME is keen to facilitate further mathematical interactions between Europe (via the EMS and its member societies) and South America.

- The rival bids for hosting the 8th ECM in 2020 were presented, with Klavdija Kutnar presenting the bid for Portorož, Slovenia, and Juan González-Meneses presenting that for Sevilla, Spain.

\section{Discussion on Mathematical Education}

The meeting then held an open discussion of Mathematical Education. A focus was the balance between challenging 'gifted' students on one hand, and, on the other, attaining a decent level for all students enrolled on mathematics courses. This latter group is increasing in size, because of the need for mathematical skills in subjects such as engineering and natural sciences. Approaches vary from country to country. For example, Hungary and Romania have special programs for gifted students. However, these countries also feel the effects of 'brain drain', with many high-achieving students opting to study abroad after high school.

With this shifting balance, and also as a consequence of the OECD Programme for International Student As- sessment (PISA) survey, mathematics curricula are undergoing transformations in many countries. The meeting agreed that is vital to exchange information about this changing landscape.

In Germany, a catalogue has been compiled of the minimal requirements that students should meet when finishing secondary school, to study engineering or natural sciences. Of course, its contents are controversial. The meeting considered whether the EMS Education Committee might play a role in drafting standards of this kind, which could then be used as guidelines in national discussions. A number of presidents recommended becoming directly, personally involved in national curriculum committees.

Another area of significant difference between countries is that of teacher training. In some countries, this is completely separate from standard university education. In other countries, there are multiple tracks to become a teacher, via a university degree or via a teacher training school. In some countries there are special schemes to support a later career change into teaching. There was a general agreement that the Education Committee should become more directly involved with issues of mathematics education at secondary school, curriculum planning, and teacher training. It is also recommended that the Education Committee should work with the EMS sponsored EuroMath initiative, aimed at students between 9 and 18. (See www.euromath.org.)

\section{Other Business}

The Chair discussed the political situation in Turkey where a colleague was imprisoned for signing the Academics For Peace petition. He reported that he had written letters of concern, on behalf of the European Mathematical Society, to the Turkish prime minister and to the President of the European Parliament. The meeting was unanimously supportive of this initiative. It was agreed to follow developments closely and also to investigate what steps might be taken at a national level to express the strong concern of our community about the situation.

\section{Closing}

On behalf of all participants, the Chair thanked the local organizers for their excellent preparations, and for the generous hospitality offered by the Alfred Rényi Institute of Mathematics of the Hungarian Academy of Sciences.

The next meeting of Presidents of Mathematical Societies will be held in the Spring of 2017 in Lisbon, hosted by the Portuguese Mathematical Society. 